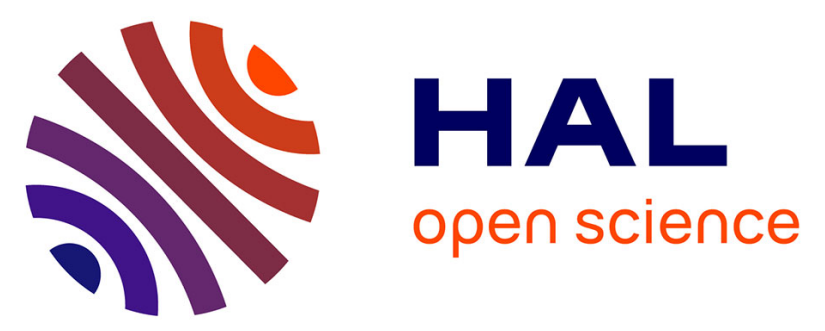

\title{
Impact of Polylactide Fluorinated End-Group Lengths and Their Dynamics on Perfluorohexane Microcapsule Morphology
}

Guilherme Picheth, Laurence Moine, Sophie Houvenagel, Leociley Menezes, Guilherme L Sassaki, Camille Dejean, Nicolas Huang, Rilton Alves de Freitas, Nicolas Tsapis

\section{To cite this version:}

Guilherme Picheth, Laurence Moine, Sophie Houvenagel, Leociley Menezes, Guilherme L Sassaki, et al.. Impact of Polylactide Fluorinated End-Group Lengths and Their Dynamics on Perfluorohexane Microcapsule Morphology. Macromolecules, 2019, 52 (6), pp.2589-2596. 10.1021/acs.macromol.9b00217 . hal-02323672

\section{HAL Id: hal-02323672 https://hal.science/hal-02323672}

Submitted on 22 Oct 2019

HAL is a multi-disciplinary open access archive for the deposit and dissemination of scientific research documents, whether they are published or not. The documents may come from teaching and research institutions in France or abroad, or from public or private research centers.
L'archive ouverte pluridisciplinaire HAL, est destinée au dépôt et à la diffusion de documents scientifiques de niveau recherche, publiés ou non, émanant des établissements d'enseignement et de recherche français ou étrangers, des laboratoires publics ou privés. 


\section{Impact of polylactide fluorinated-end group length and their dynamics on perfluohexane microcapsules morphology}

Guilherme F. Picheth $^{\mathrm{a}, \mathrm{c}}$, Laurence Moine ${ }^{\mathrm{a}^{*}}$, Sophie Houvenagel ${ }^{\mathrm{a}}$, Leociley R. A. Menezes ${ }^{d}$, Guilherme L. Sassaki ${ }^{d}$, Camille Dejean ${ }^{b}$, Nicolas Huang ${ }^{a}$, Rilton Alves de Freitas ${ }^{c}$, Nicolas Tsapis $^{\mathrm{a}^{*}}$

${ }^{a}$ Institut Galien Paris-Sud, CNRS, Univ. Paris-Sud, Université Paris-Saclay, 92296 Châtenay-Malabry, France.

${ }^{\mathrm{b}}$ BioCIS, CNRS, Univ. Paris-Sud, Université Paris-Saclay, 92296 Châtenay-Malabry, France.

${ }^{\mathrm{C}}$ Biopol, Chemistry Department, Federal University of Paraná, 81531-908 Curitiba, PR, Brazil.

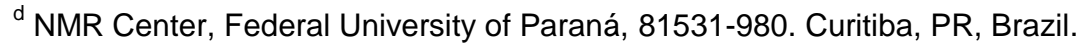

* Corresponding authors at: Institut Galien Paris-Sud, CNRS, Univ. Paris-Sud, Université ParisSaclay, 92296 Châtenay-Malabry. E-mail address: laurence.moine@u-psud.fr (Laurence Moine), nicolas.tsapis@u-psud.fr (Nicolas Tsapis).

Keywords: Perfluorocarbon microcapsules, perfluorohexane, fluorinated polymers, focused ultrasound, end-group dynamics, fluorous interaction 
Table of Content Graphic

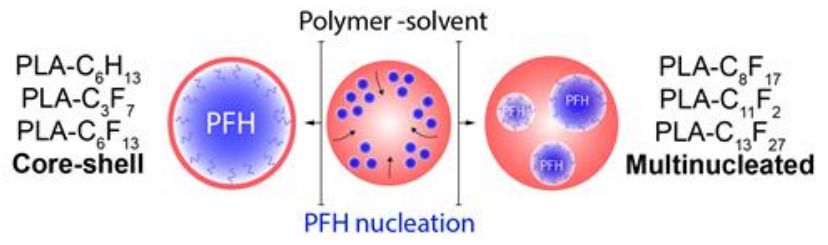




\section{Abstract}

2 We have synthesized polylactide (PLA) polymers containing five distinct lengths of

3 fluorinated end-groups (from $\mathrm{C}_{3} \mathrm{~F}_{7}$ to $\mathrm{C}_{13} \mathrm{~F}_{27}$ ). The influence of fluorinated end-groups length

4 and their dynamics in chlorinated solvents (chloroform and dichloromethane) was

5 investigated as a function of the presence of perfluohexane (PFH) and related to the

6 morphology of capsules of PFH obtained using these fluorinated polylactides. ${ }^{19} \mathrm{~F}$ spin-spin

7 relaxation time $\left(T_{2}\right)$ measurements revealed a reduced mobility of the fluorinated units with

8 dependency on fluorinated chain length in the order $\mathrm{C}_{3} \mathrm{~F}_{7}>\mathrm{C}_{8} \mathrm{~F}_{17}>\mathrm{C}_{13} \mathrm{~F}_{27}$. The presence of

9 perfluorohexane (PFH) led to a further decrease on the segmental mobility, indicating the

10 existence of fluorous interactions. The $\mathrm{T}_{2}$ relaxation time of the $\mathrm{CF}_{3}$ resonance of $\mathrm{PLA}-\mathrm{C}_{3} \mathrm{~F}_{7}$

11 decreased from $540 \pm 50 \mathrm{~ms}$ in $\mathrm{CDCl}_{3}$ to $81 \pm 15 \mathrm{~ms}$ after the addition of PFH. Due to these

12 fluorous interactions, PLA polymers containing short fluorinated groups $\left(\mathrm{C}_{3} \mathrm{~F}_{7}\right.$ and $\left.\mathrm{C}_{6} \mathrm{~F}_{13}\right)$ led

13 to microcapsules with core-shell morphologies, whereas those formulated with long F-units

$14 \quad\left(\mathrm{C}_{8} \mathrm{~F}_{17}, \mathrm{C}_{11} \mathrm{~F}_{23}\right.$ and $\left.\mathrm{C}_{13} \mathrm{~F}_{27}\right)$ favored the formation of multinucleated capsules as observed by

15 confocal microscopy. 


\section{Introduction}

Fully and partly fluorinated compounds are widely explored in the chemical industry and academic research for their inherent immiscibility with hydrophobic and lipophobic solvents. This so-called "fluorophilic" character is responsible for low or "gas like" intermolecular attractions which confer to such molecules inertness and biocompatibility, features that attracted special attention for a wide range of biomedical applications ${ }^{1,2}$. In particular, liquid perfluorocarbons (PFCs), such as perfluorohexane (PFH) or perfluorooctyl bromide (PFOB) are described to be minimally absorbed, eliminated from the lungs by evaporation and did not lead to any significant histological, cellular or biochemical disturbance ${ }^{3}$. Therefore, these PFCs are intensively investigated for their potential to act as intravascular contrast agents ${ }^{4}$.

Recent reports describe the use of capsules containing PFOB to provide in vivo ${ }^{19} \mathrm{~F}-\mathrm{MRI}$ or ultrasound detection and also passively deliver chemotherapeutics to cancer cells ${ }^{5-9}$. Similar formulations use PFH as an active core for its lower boiling point, as it favors liquid-to-gas transition by acoustic and thermal stimuli, allowing real-time ultrasonic imaging as well as localized drug-release ${ }^{10-12}$. Nonetheless, the entrapment of fully fluorinated PFCs, such as $\mathrm{PFH}$, within a polymeric shell is proving to be difficult due to their dual lipophobic and hydrophobic character and their trend to easily evaporate during formulation ${ }^{14}$. Several groups have turned to the use of fluorinated surfactants or lipids to improve PFCs encapsulation ${ }^{15-17}$. Literature also reports the functionalization of polymer with fluorinated end-groups to favor interactions with PFCs ${ }^{11,14,18-24}$. It was previously demonstrated that a wide range of fluorinated end-groups linked to the PLA chain - from $\mathrm{C}_{3} \mathrm{~F}_{7}$ to $\mathrm{C}_{13} \mathrm{~F}_{27}-$ increased the entrapment of PFCs into nanocapsules, resulting in more efficient acoustic responses $^{14,19}$. However, no significant distinction regarding the morphology or PFC entrapment was observed by increasing the length of the end-fluorinated groups in nanoformulations. 
47 The main objective of this study is to investigate deeper the influence and extent of fluorous 48 interactions between fluorinated end-groups of $\mathrm{PLA}-\mathrm{C}_{x} \mathrm{~F}_{2 x+1}$ and $\mathrm{PFH}$ on the final morphology 49 of microcapsules (MC) as a function of fluorinated end-group length. In particular, we 50 examine the role of the solvent in which the polymer was dissolved on the strength of 51 fluorous interactions by comparing chloroform and dichloromethane, two solvents often used 52 to formulate polymer particles and capsules ${ }^{25,26}$. To fully explore the impact of fluorinated 53 end-group chain length and solvent, end-group dynamics and PFH entrapment efficiency 54 were evaluated by NMR and MC morphology was assessed by confocal microscopy. This 55 study provides information for the morphological design of new ultrasound activable systems formulated with fluorinated PLA polymers. 


\section{Materials and Methods}

\subsection{Materials}

D,L-lactide was purchased from Polysciences (Germany) and perfluorohexane $98+\%$ was acquired from Alfa Aesar (Germany). 1-hexanol was obtained from Acros Organics (Belgium), 2,2,3,3,4,4-heptafluoro-1-butanol, 1H,1H perfluoro-1-heptanol, $1 \mathrm{H}, 1 \mathrm{H}$ perfluoro-1nonanol, $1 \mathrm{H}, 1 \mathrm{H}$ perfluoro-1-dodecanol and $1 \mathrm{H}, 1 \mathrm{H}$ perfluoro-1-tetradecanol were acquired from Fluorochem (United Kingdom). Acetone, tetrahydrofuran (THF) and dichloromethane were purchased from Carlo Erba Reactifs (France), chloroform and diethyl ether from VWR (France). Nile red, stannous octoate, sodium cholate, trifluoroacetic acid (TFA), deuterated chloroform and deuterated dichloromethane were provided by Sigma-Aldrich (France). The ultrapure water was produced by a RIOS/Milli-Q system (Millipore, France), with a resistivity of $18.2 \mathrm{M} \Omega \mathrm{cm}$. The NMR sample tubes and coaxial inserts were obtained from CortecNet (France).

\subsection{Polymer Synthesis}

All fluorinated (PLA- $\mathrm{C}_{3} \mathrm{~F}_{7}, \mathrm{PLA}-\mathrm{C}_{6} \mathrm{~F}_{13}, \mathrm{PLA}-\mathrm{C}_{8} \mathrm{~F}_{17}, \mathrm{PLA}-\mathrm{C}_{11} \mathrm{~F}_{23}$ and PLA- $\mathrm{C}_{13} \mathrm{~F}_{27}$ ) and nonfluorinated (PLA- $\mathrm{C}_{6} \mathrm{H}_{13}$ ) derivatives of polylactide polymers were synthesized by ring opening polymerization (ROP) with the presence of stannous octoate as catalyst ${ }^{27,28}$. All glassware and stir bars were flame-dried and cooled under argon flow. Briefly, in a $10 \mathrm{~mL}$ schlenck tube equipped with a magnetic stir-bar, the D,L-lactide $(10.4 \mathrm{mmol}, 1.5 \mathrm{~g})$ and corresponding initiator $(0.075 \mathrm{mmol})$ - 1-hexanol for PLA- ${ }_{6} \mathrm{H}_{13}, 2,2,3,3,4,4$-heptafluoro-1-butanol for PLA$\mathrm{C}_{3} \mathrm{~F}_{7}, 1 \mathrm{H}, 1 \mathrm{H}$ perfluoro-1-heptanol for PLA- $\mathrm{C}_{6} \mathrm{~F}_{13}, 1 \mathrm{H}, 1 \mathrm{H}$ perfluoro-1-nonanol for PLA- $\mathrm{C}_{8} \mathrm{~F}_{17}$, $1 \mathrm{H}, 1 \mathrm{H}$ perfluoro-1-dodecanol for $\mathrm{PLA}-\mathrm{C}_{11} \mathrm{~F}_{23}$ or $1 \mathrm{H}, 1 \mathrm{H}$ perfluoro-1-tetradecanol for PLA$\mathrm{C}_{13} \mathrm{~F}_{27}$ - were added to the flask under argon flow. The tube was sealed with a rubber cap and a stannous octoate solution $(0.05 \mathrm{mmol}, 20 \mathrm{mg})$ dissolved in $2 \mathrm{~mL}$ of dried toluene was added through the septum. The tube was purged with argon for $0.5 \mathrm{~h}$ and the polymerization reaction was conducted with continuous stirring at $130^{\circ} \mathrm{C}$ for 55 minutes in an oil bath under 
argon flow. The reaction was quenched by immersing the flask in a cold water bath. Afterwards, the solvent was evaporated under reduced pressure for $1 \mathrm{~h}$ and the material was dissolved in $5 \mathrm{~mL}$ of chloroform. The product was purified by precipitation as previously described $^{29}$ : all polymers were precipitated into cold diethyl ether $(80 \mathrm{~mL})$, next, PLA- ${ }_{6} \mathrm{H}_{13}$ was dissolved into THF ( $5 \mathrm{~mL}$ ), whereas the fluorinated polymers were dissolved in acetone $(20 \mathrm{~mL})$ and precipitated again in ultrapure water $(150 \mathrm{~mL})$. The samples were freeze-dried for $24 \mathrm{~h}$ and a white powder was obtained. Lactide conversion $\geq 95 \%$ ( $\left.{ }^{1} \mathrm{H}-\mathrm{NMR}\right)$. ${ }^{1} \mathrm{H}-\mathrm{NMR}$ [400 MHz, $\left.\mathrm{CDCl}_{3}, 2^{\circ} \mathrm{C}\right]$ PLA-C ${ }_{6} \mathrm{H}_{13}: \delta_{\mathrm{H}}$ 5.10-5.28 (PLA-CHCH${ }_{3} \mathrm{COO}$ ), 1.52-1.61 (PLA$\left.\mathrm{CHCH}_{3} \mathrm{COO}-\right)$, 0.88-0.92 (- $\left.\mathrm{CH}_{2} \mathrm{CH}_{3}\right)$. PLA- $\mathrm{C}_{3} \mathrm{~F}_{7}$, PLA-C $\mathrm{C}_{6} \mathrm{~F}_{13}$, PLA-C $\mathrm{F}_{8} \mathrm{~F}_{17}$, PLA-C $_{11} \mathrm{~F}_{23}$ and PLA-C $_{13} \mathbf{F}_{27}: \delta_{\mathrm{H}}$ 5.10-5.28 (PLA-CHCH$\left.{ }_{3} \mathrm{COO}\right)$ ), 4.50-4.70 (-OCH $\left.\mathrm{CF}_{2^{-}}\right)$, 1.52-1.61 (PLA$\left.\mathrm{CHCH}_{3} \mathrm{COO}-\right) .{ }^{19} \mathrm{~F}-\mathrm{NMR}\left[400 \mathrm{MHz}, \mathrm{CDCl}_{3}, 25^{\circ} \mathrm{C}\right] \mathbf{P L A}_{-} \mathbf{C}_{3} \mathbf{F}_{7}: \delta_{\mathrm{F}}-79.0\left(-\mathrm{CF}_{3}\right),-118.7$ (-

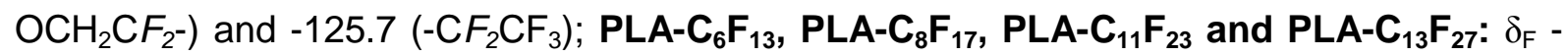
$78.9\left(-\mathrm{CF}_{3}\right),-117.7\left(-\mathrm{OCH}_{2} \mathrm{CF}_{2^{-}}\right),-120.0\left(-\left(\mathrm{CF}_{2}\right)_{n} \mathrm{CF}_{2} \mathrm{CF}_{3}\right),-120.7\left(-\mathrm{OCH}_{2} \mathrm{CF}_{2} \mathrm{CF}_{2} \mathrm{CF}_{2^{-}}\right),-121.4$ $\left(-\mathrm{OCH}_{2} \mathrm{CF}_{2} \mathrm{CF}_{2^{-}}\right)$and -124.2 $\left(-\mathrm{CF}_{2} \mathrm{CF}_{3}\right)$.

\subsection{Characterization}

All polymers were characterized by size exclusion chromatography (SEC) in chloroform at 30 ${ }^{\circ} \mathrm{C}$ with a flow rate of $1 \mathrm{~mL} \cdot \mathrm{min}^{-1}$ by two columns (PL-gel $5 \mu \mathrm{m}$ MIXED-D $300 \times 7.5 \mathrm{~mm}$ ) calibrated against a curve based on poly(methyl methracrylate) standards (PMMA, Polymer Laboratories, Varian Inc.) The system was coupled to a refractive index detector (Spectrasystem RI-150, Thermo Electro Corp.). ${ }^{1} \mathrm{H}$ and ${ }^{19} \mathrm{~F}-\mathrm{NMR}$ spectra were obtained on a Bruker AVANCE III HD $400 \mathrm{MHz}$ in $\mathrm{CDCl}_{3}$ at $25^{\circ} \mathrm{C}$.

\subsection{Interfacial surface tension}

The interfacial surface tension was performed in a Tracker tensiometer (Teclis, France). PFH was previously filtrated by a column of aluminum oxide. A constant $2 \mu \mathrm{L}$ PFH or sodium cholate drop was formed by a syringe and a G20 stainless steel needle inside an optical glass cuvette containing fixed polymer concentrations of $25 \mathrm{mg} \cdot \mathrm{mL}^{-1}$ in chloroform or 
dichloromethane previously filtered by $0.22 \mu \mathrm{m}$ (Millipore). The temperature was kept at 20 ${ }^{\circ} \mathrm{C}$ and the interfacial surface tension was determined from the drop profile employing the Laplace equation and the forces balance between capillarity and gravity.

\section{$2.5{ }^{19} \mathrm{~F}-\mathrm{NMR} \mathrm{T}_{1}$ and $\mathrm{T}_{2}$ Relaxation}

${ }^{19} \mathrm{~F}$ Spin-lattice and spin-spin relaxation measurements were performed at $25{ }^{\circ} \mathrm{C}$ in $\mathrm{CDCl}_{3}$ or $\mathrm{CD}_{2} \mathrm{Cl}_{2}$ with fixed polymer concentrations of $25 \mathrm{mg} \cdot \mathrm{mL}^{-1}$. Samples containing $15 \mu \mathrm{L}$ of $\mathrm{PFH}$ were also evaluated. The samples were not degassed. All experiments were performed on a Bruker AVANCE III HD NMR spectrometer operating at $9.4 \mathrm{~T}$, equipped with a 5-mm multinuclear inverse detection probe, observing ${ }^{19} \mathrm{~F}$ and ${ }^{1} \mathrm{H}$ nuclei at 376.49 and $400.13 \mathrm{MHz}$, respectively. ${ }^{19} \mathrm{~F} T_{1}$ was determined by the inversion-recovery pulse sequence $\left(T_{1} I R\right)$. The delay $(\tau)$ between the inversion and read-pulse was varied along 16 values (1 to $22 \mathrm{~s}$ ). The total number of scans was 32 , spectral width $=100 \mathrm{ppm}$ and relaxation delay $=22 \mathrm{~s} .{ }^{19} \mathrm{~F} \mathrm{~T}_{2}$ values were measured by the PROJECT-CPMG pulse sequence along 15 values of $\tau$ ( 0.1 to $2 \mathrm{~ms})^{30}$. The number of scans was 128 , spectral width $=100 \mathrm{ppm}$ and relaxation delay $=10$ s. Relaxation times were obtained by nonlinear least-squares fitting of a mono- exponential function with $r^{2} \geq 0.998$ for all samples.

\subsection{Microcapsules Formulation}

Microcapsules were prepared by the emulsion-evaporation technique, as previously described ${ }^{13}$, with minor modifications. Briefly, the desired amount of polymer was dissolved into $2 \mathrm{~mL}$ of chloroform or dichloromethane in a $50 \mathrm{~mL}$ glass flask. Afterwards, $50 \mu \mathrm{L}$ of nile red $\left(55 \mu \mathrm{g} \cdot \mathrm{mL}^{-1}\right)$ was added and the flask was sealed with a rubber cap. Next, $30 \mu \mathrm{L}$ of PFH was introduced through the septum with constant stirring and the media was emulsified with $10 \mathrm{~mL}$ of sodium cholate $1.5 \%(\mathrm{w} / \mathrm{w})$ at $4{ }^{\circ} \mathrm{C}$. The mixture was submitted to high-speed homogenization at 8.000 RPM using an Ultra-Turrax T25 (IKA) coupled with an SN25-10G dispersing tool in an ice bath for 1 minute. The solvent was removed by rotary evaporation 
136 (Büchi) with a $30^{\circ} \mathrm{C}$ water bath and recirculation chiller at $-10^{\circ} \mathrm{C}$. A vacuum gradient from 400 to 30 mbar in 7 steps of 5 minutes was employed. Afterwards, the total volume of each sample was completed to $10 \mathrm{~mL}$ with ultrapure water.

\subsection{Confocal Microscopy}

Microcapsules were washed twice with ultrapure water by centrifugation and resuspended in glycerol to minimize motion. All samples were observed in a Leica TCS SP5 confocal scanning microscope (Leica) with a $1 \mathrm{~mW}$ helium neon laser operating at excitation of 551 $\mathrm{nm}$ and $636 \mathrm{~nm}$ of emission, Plan Achromat 63X objective (NA 1.40 oil immersion) and pinhole diameter at $71 \mathrm{~nm}$. For diameter analysis, the measurements were performed in the equatorial plane of each capsule as previously described ${ }^{13}$.

\subsection{Scanning Electron Microscopy}

Scanning electron microscopy was performed in a Merlin 6040 (Carl Zeiss, Germany) operating at $3 \mathrm{kV}$. All microcapsules were washed twice with ultrapure water by centrifugation to remove the excess of sodium cholate, deposited on carbon conductive double-sided tape (Euro-medex, France) and dried at room temperature. Afterwards, they were coated with a palladium-platinum layer of about $3 \mathrm{~nm}$ using a Cressington sputtercoater $208 \mathrm{HR}$ with a rotary-planetary-tilt stage, fitted with an MTM-20 thickness controller.

\subsection{PFH encapsulation efficiency by ${ }^{19}$ F-NMR spectroscopy}

For PFH quantification, $1 \mathrm{~mL}$ of microcapsules was freeze-dried during $24 \mathrm{~h}$ employing an Alpha-1-2 LD apparatus (Christ). The flasks were hermetically sealed with a rubber cap and stored at $-20{ }^{\circ} \mathrm{C}$ until analysis. The PFH encapsulation efficiency was determined as described by Diou et al. ${ }^{29}$. A total volume of $1 \mathrm{~mL}$ of chloroform was introduced into the sealed tube by a needle, the suspension was vortexed (5 cycles of 30 seconds) and centrifuged at $0{ }^{\circ} \mathrm{C}$ for 10 minutes at $5000 \mathrm{rpm}$ (Jouan CR4I centrifuge, Thermo Electron Corporation). The organic solution was collected in a cold room at $4{ }^{\circ} \mathrm{C}$ and introduced into 
161 an NMR tube that was afterwards loaded with a stem coaxial insert containing TFA in $\mathrm{D}_{2} \mathrm{O}$

$162\left(12 \mu \mathrm{mol} \cdot \mathrm{mL}^{-1}\right)$ as external standard ${ }^{31}$. All spectra were obtained at $4^{\circ} \mathrm{C}$ on a Bruker Avance $163300(400 \mathrm{MHz})$ spectrometer. The total amount of encapsulated PFH was determined based 164 on a PFH calibration curve. For each MC sample, the integration of the TFA peak at -76.5 $165 \mathrm{ppm}$ was determined as 3 and the resulting integration of the $\mathrm{PFH} \mathrm{CF}_{3}$ at $-81.2 \mathrm{ppm}$ was 166 used to calculate the PFH concentration in the NMR tube based to the equation of the 167 calibration curve.

\subsection{Statistical analysis}

169 The statistical analysis was performed using Statistica ${ }^{\text {TM }} 8.0$ software (StatSoft Inc., Tulsa, 170 USA). The data was analyzed by two-sided Student's $t$-test and a statistical significance was 171 set at the level of $p<0.05$. 


\section{Results and Discussion}

173

174

175

176

177

178

179

180

181

182

183

\subsection{Polymers synthesis and characterization}

Six end-group fluorinated or alkylated polymers were synthesized by ring opening polymerization of $\mathrm{D}, \mathrm{L}$-lactide with appropriate initiator (hexanol or fluorinated alcohols) as previously described ${ }^{14,19,28,32}$ (reaction yield > 85\%). The polylactide main chain is constituted by $\sim 140$ repetitive units containing different lengths of end fluorinated-groups: polymers are designated according to the terminal group chemistry and length of fluorinated units as PLA- $\mathrm{C}_{6} \mathrm{H}_{13}$, PLA- $\mathrm{C}_{3} \mathrm{~F}_{7}$, PLA- $\mathrm{C}_{6} \mathrm{~F}_{13}$, PLA- $\mathrm{C}_{8} \mathrm{~F}_{17}$, PLA- $\mathrm{C}_{11} \mathrm{~F}_{23}$ and PLA- $\mathrm{C}_{13} \mathrm{~F}_{27}$. They were characterized by ${ }^{1} \mathrm{H}$ and ${ }^{19} \mathrm{~F}-\mathrm{NMR}$ and exhibited a molecular weight around 18000 21000 g. $\mathrm{mol}^{-1}$ as assessed by NMR, with a narrow dispersity (Supporting information Figure S1 and Table S1).

\subsection{Polymers dynamics}

To explore the role and extent of fluorous interactions between the different PLA- $\mathrm{C}_{x} \mathrm{~F}_{2 \mathrm{x}+1}$ and $\mathrm{PFH}$ during the formation of microcapsules, we have investigated interfacial properties, dynamics in solution as well as morphological features generated by each of these polymers. As fluorine recognition and compartmentalization are strictly dependent on the solvent's character, the behavior and impact of polymer end-group chemistry was studied in two distinct solvents usually employed in the formulation of $\mathrm{MC}$, namely, chloroform and dichloromethane $e^{25,26}$.

The interfacial activity of the polymers was determined at the solvent/PFH and solvent/sodium cholate (SC) interfaces by interfacial surface tension measurements (Table 1). At the solvent/SC interface, interfacial tension values were between $7-8 \mathrm{mN} \cdot \mathrm{m}^{-1}$ in $\mathrm{CHCl}_{3}$ or $\mathrm{CH}_{2} \mathrm{Cl}_{2}$, for all polymers, suggesting no specific solvent or end-group contribution to the interfacial activity. At the PFH/solvent interface, polymers dissolved in $\mathrm{CHCl}_{3}$ exhibited an interfacial tension average value of $3.0 \pm 0.05 \mathrm{mN} . \mathrm{m}^{-1}$ whereas $6.0 \pm 0.1 \mathrm{mN} \cdot \mathrm{m}^{-1}$ was measured for polymers dissolved in $\mathrm{CH}_{2} \mathrm{Cl}_{2}$, indicating that $\mathrm{CHCl}_{3}$ favors $\mathrm{PFH}$ spreading. Nonetheless, 
none of the polymers was able to decrease the interfacial tension compared to the solvent itself regardless the end-group chemistry or the length of the fluorinated end-group.

Table 1. Interfacial tensions at the perfluorohexane/solvent and alkylated or fluorinated polymer/sodium cholate $1.5 \%(\mathrm{w} / \mathrm{v})$ interfaces. All polymers were dissolved at $25 \mathrm{mg} \cdot \mathrm{mL}^{-1}$ in chloroform or dichloromethane. All results are expressed in $\mathrm{mN} \cdot \mathrm{m}^{-1}$.

\begin{tabular}{|l|c|c|c|c|}
\cline { 2 - 5 } \multicolumn{1}{c|}{} & \multicolumn{2}{c|}{ Chloroform } & \multicolumn{2}{c|}{ Dichloromethane } \\
\hline & PFH/solvent & Solvent/SC 1.5\% & PFH/solvent & Solvent/SC 1.5\% \\
\hline Solvent & $3.2 \pm 0.3$ & $7.5 \pm 0.3$ & $6.0 \pm 0.3$ & $8.1 \pm 0.2$ \\
\hline PLA-C ${ }_{6} \mathbf{H}_{13}$ & $3.0 \pm 0.5$ & $7.5 \pm 0.2$ & $6.2 \pm 0.5$ & $8.0 \pm 0.2$ \\
\hline PLA-C ${ }_{3} F_{7}$ & $3.0 \pm 0.3$ & $7.0 \pm 0.1$ & $6.1 \pm 0.7$ & $7.5 \pm 0.3$ \\
\hline PLA-C ${ }_{6} \mathbf{F}_{13}$ & $3.0 \pm 0.5$ & $7.1 \pm 0.5$ & $6.2 \pm 0.4$ & $7.7 \pm 0.5$ \\
\hline PLA-C ${ }_{8} F_{17}$ & $3.1 \pm 0.4$ & $7.1 \pm 0.2$ & $5.9 \pm 0.4$ & $7.7 \pm 0.4$ \\
\hline PLA-C ${ }_{11} F_{23}$ & $3.0 \pm 0.3$ & $7.2 \pm 0.3$ & $5.9 \pm 0.3$ & $7.8 \pm 0.2$ \\
\hline PLA-C ${ }_{13} F_{27}$ & $3.1 \pm 0.4$ & $7.4 \pm 0.1$ & $6.1 \pm 0.4$ & $7.6 \pm 0.1$ \\
\hline
\end{tabular}

The lack of adsorption at the $\mathrm{PFH} /$ solvent interface might be explained by the mass ratio difference between the relatively small fluorinated blocks compared to the PLA main chain $\left(\mathrm{C}_{3}\right.$ to $\mathrm{C}_{13}$ for fluorinated block vs. 140 repetitive units for $\left.\mathrm{PLA}\right)$ and the conformation assumed by the polymer in solution. Indeed, as the PLA polymers are well solvated in $\mathrm{CHCl}_{3}$ and $\mathrm{CH}_{2} \mathrm{Cl}_{2}$ (Hildebrand solubility parameter $\left(\delta_{T}\right)$ of $20.8 \mathrm{MPa}^{0.5}$ for unmodified PLA, 18.7 $\mathrm{MPa}^{0.5}$ for $\mathrm{CHCl}_{3}$ and $20.2 \mathrm{MPa} a^{0.5}$ for $\mathrm{CH}_{2} \mathrm{Cl}_{2}{ }^{33}$ ), a conformational rearrangement based on the higher solubility of the polymeric chains within the solvents may hide the fluorinated groups inside the PLA coil, hindering an effective interaction with the PFH phase ${ }^{19}$.

Although no interfacial activity was observed at the PFH/solvent interface during static measurements, the solvent-evaporation process is dynamic and associated with transitory interfacial instabilities due to system disorganization ${ }^{34}$. Such constant rearrangement of water and organic solvent molecules may promote the formation of fluorinated domains 
216 favorable for PFH encapsulation ${ }^{35}$. Indeed, many studies carried on mixed systems, 217 containing both fluorocarbons and organic solvents, showed the tendency of perfluoralkyl 218 moieties to self-associate and generate fluorous compartments. This aggregation in rich 219 fluorous domains is generally associated to a reduced mobility of fluorinated groups ${ }^{26,36,37}$.

220 To assess the behavior of the fluorinated chains in a more dynamic media containing PFH -

221 a situation similar to what happens prior to solvent evaporation - the end-group mobility of 222 three fluorinated polymers, PLA- $\mathrm{C}_{3} \mathrm{~F}_{7}, \mathrm{PLA}-\mathrm{C}_{8} \mathrm{~F}_{17}$ and $\mathrm{PLA}-\mathrm{C}_{13} \mathrm{~F}_{27}$, was analyzed by fluorine 223 NMR spectroscopy employing spin-lattice $\left(T_{1}\right)$ and spin-spin $\left(T_{2}\right)$ relaxation measurements at 224 fixed polymer concentration of $25 \mathrm{mg} \cdot \mathrm{mL}^{-1}$ and $15 \mu \mathrm{L}$ of $\mathrm{PFH}$ (corresponding to the 225 formulation conditions). Accordingly, the $\mathrm{CF}_{3}$ group dynamics in each solvent was probed in 226 presence and absence of PFH in the solvent. Unfortunately, some of the PFH resonances 227 overlapped with the $\mathrm{CF}_{3}$ polymer signals for $\mathrm{PLA}-\mathrm{C}_{8} \mathrm{~F}_{17}$ and $\mathrm{PLA}-\mathrm{C}_{13} \mathrm{~F}_{27}$ in both solvents. Only 228 PLA-C ${ }_{3} F_{7}$ exhibited well segregated resonance from those of PFH because of the different 229 chemical environments, which permitted a resonance shift towards lower magnetic fields, not 230 overlapping with $\mathrm{PFH}$ as displayed in Figure 1. The nomenclature and ${ }^{19} \mathrm{~F}-\mathrm{NMR}$ peak 231 labeling consists alphabetically with the position of the fluorinated resonance respective to 232 the PLA chain ${ }^{38,39}$. 


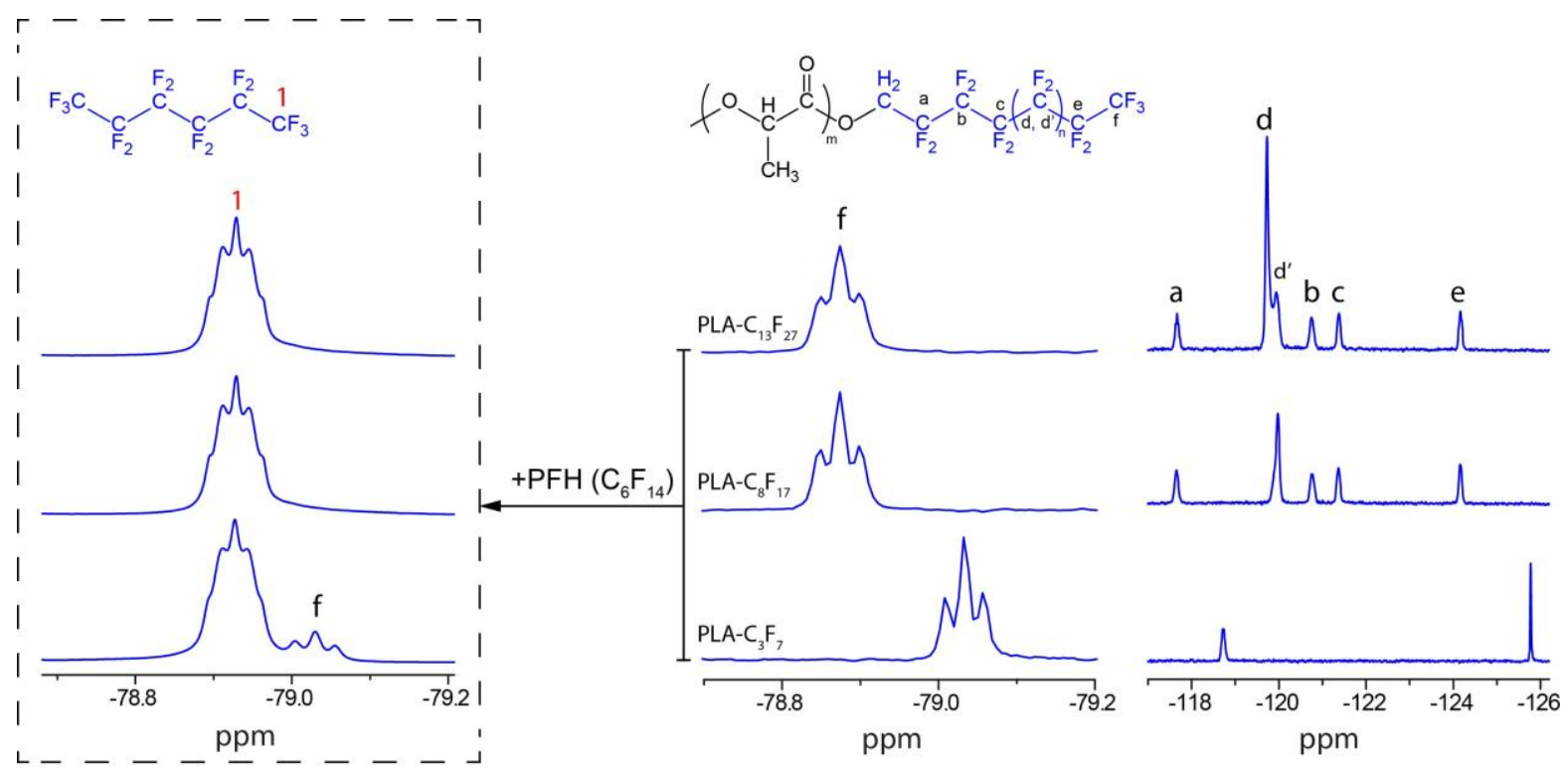

Figure 1. Magnified $\mathrm{CF}_{3}$ and $\mathrm{CF}_{2}$ regions of the ${ }^{19} \mathrm{~F}-\mathrm{NMR}$ spectra for $\mathrm{PLA}-\mathrm{C}_{3} \mathrm{~F}_{7}, \mathrm{PLA}-\mathrm{C}_{8} \mathrm{~F}_{17}$ and PLA- $\mathrm{C}_{13} \mathrm{~F}_{27}$ in $\mathrm{CDCl}_{3}$. The insets (left) exhibit the $\mathrm{CF}_{3}$ resonance in a mixed system of polymer and perfluorohexane. ${ }^{19} \mathrm{~F}$ peak assignment is indicated in the top of each image.

$\mathrm{T}_{2}$ analysis revealed that the $\mathrm{CF}_{3}$ resonance mobility decreased strongly for polymers functionalized with longer fluorinated units in the order $\mathrm{C}_{3} \mathrm{~F}_{7}>\mathrm{C}_{8} \mathrm{~F}_{17}>\mathrm{C}_{13} \mathrm{~F}_{27}$ for both solvents (Table 2). Such reduction in the local fluorine dynamics according to chain length is related to the strong electronegativity of the $\mathrm{C}-\mathrm{F}$ bond that generates linear and rigid chain 242 conformations, reducing the segmental mobility as the chain length increases ${ }^{40}$. Nonetheless, samples dissolved in $\mathrm{CDCl}_{3}$ showed smaller relaxation values compared to their counterparts prepared in $\mathrm{CD}_{2} \mathrm{Cl}_{2}$ : this effect is clearly illustrated by the $\mathrm{CF}_{3}$ resonance of PLA- $\mathrm{C}_{3} \mathrm{~F}_{7}$, with $\mathrm{T}_{2}$ of $540 \pm 50 \mathrm{~ms}$ in $\mathrm{CDCl}_{3}$ and $1530 \pm 150 \mathrm{~ms}$ in $\mathrm{CD}_{2} \mathrm{Cl}_{2}$. Such results were also confirmed by $T_{1}$ measurements (Supporting information Table S2). These significant changes in relaxation times indicate that chloroform is not a good solvent for the fluorinated end-groups and drives self-association of ${ }^{19} \mathrm{~F}$ containing units. 
Table 2. ${ }^{19} \mathrm{~F}$ spin-spin relaxation $\left(\mathrm{T}_{2}\right)$ values of $\mathrm{CF}_{3}$ resonances for samples dissolved in deuterated chloroform or dichloromethane in presence of absence of perfluorohexane. All polymers were dissolved at fixed concentration of $25 \mathrm{mg} \cdot \mathrm{mL}^{-1}$ (Experiment performed in 253 duplicate, $n=2)$.

\begin{tabular}{|l|c|c|c|c|}
\hline \multirow{2}{*}{ Sample } & \multicolumn{2}{|c|}{$T_{2}$ (ms) } & \multicolumn{2}{c|}{$T_{2}$ (ms) } \\
\cline { 2 - 5 } & $\mathbf{C D C l}_{3}$ & $\mathbf{C D C l}_{3}+\mathrm{PFH}$ & $\mathbf{C D}_{2} \mathrm{Cl}_{2}$ & $\mathbf{C D}_{2} \mathrm{Cl}_{2}+\mathrm{PFH}$ \\
\hline PLA-C ${ }_{3} \mathrm{~F}_{7}$ & $540 \pm 50$ & $81 \pm 15$ & $1530 \pm 150$ & $1710 \pm 250$ \\
\hline PLA-C ${ }_{8} \mathrm{~F}_{17}$ & $210 \pm 20$ & --- & $1263 \pm 165$ & --- \\
\hline PLA-C ${ }_{13} \mathrm{~F}_{27}$ & $76 \pm 10$ & --- & $790 \pm 50$ & --- \\
\hline
\end{tabular}

255 Afterwards, PFH was added to each polymer solution to simulate the system behavior just before emulsification with sodium cholate. In $\mathrm{CD}_{2} \mathrm{Cl}_{2}, \mathrm{~T}_{2}$ varied from $1530 \pm 150 \mathrm{~ms}$ to $1710 \pm 250 \mathrm{~ms}$ in presence of PFH, showing that the end-group dynamics is not significantly affected by PFH addition in the media $(\mathrm{p}=0.475)$. However, in $\mathrm{CDCl}_{3}$, the $\mathrm{CF}_{3}$ signal of PLA$\mathrm{C}_{3} \mathrm{~F}_{7}$ showed a significant $\mathrm{T}_{2}$ decrease with $\mathrm{PFH}$, from $540 \pm 50 \mathrm{~ms}$ to $81 \pm 15 \mathrm{~ms}(\mathrm{p}<0.05)$.

260 This lower mobility denotes a polymer rearrangement in presence of PFH evidencing an 261 increased tendency for the fluorinated segments to associate with each other (Figure 2). 262 Indeed, in $\mathrm{CHCl}_{3}$, addition of $\mathrm{PFH}$ further decreases the solubility of the fluorinated segments 263 which promotes dipolar interactions between the fluorinated end-group and PFH. These 264 more efficient interactions in $\mathrm{CHCl}_{3}$ suggest formation of $\mathrm{F}$-rich domains where the reduced 265 mobility of the fluorinated segment leads to shorter $T_{2}$ values. 

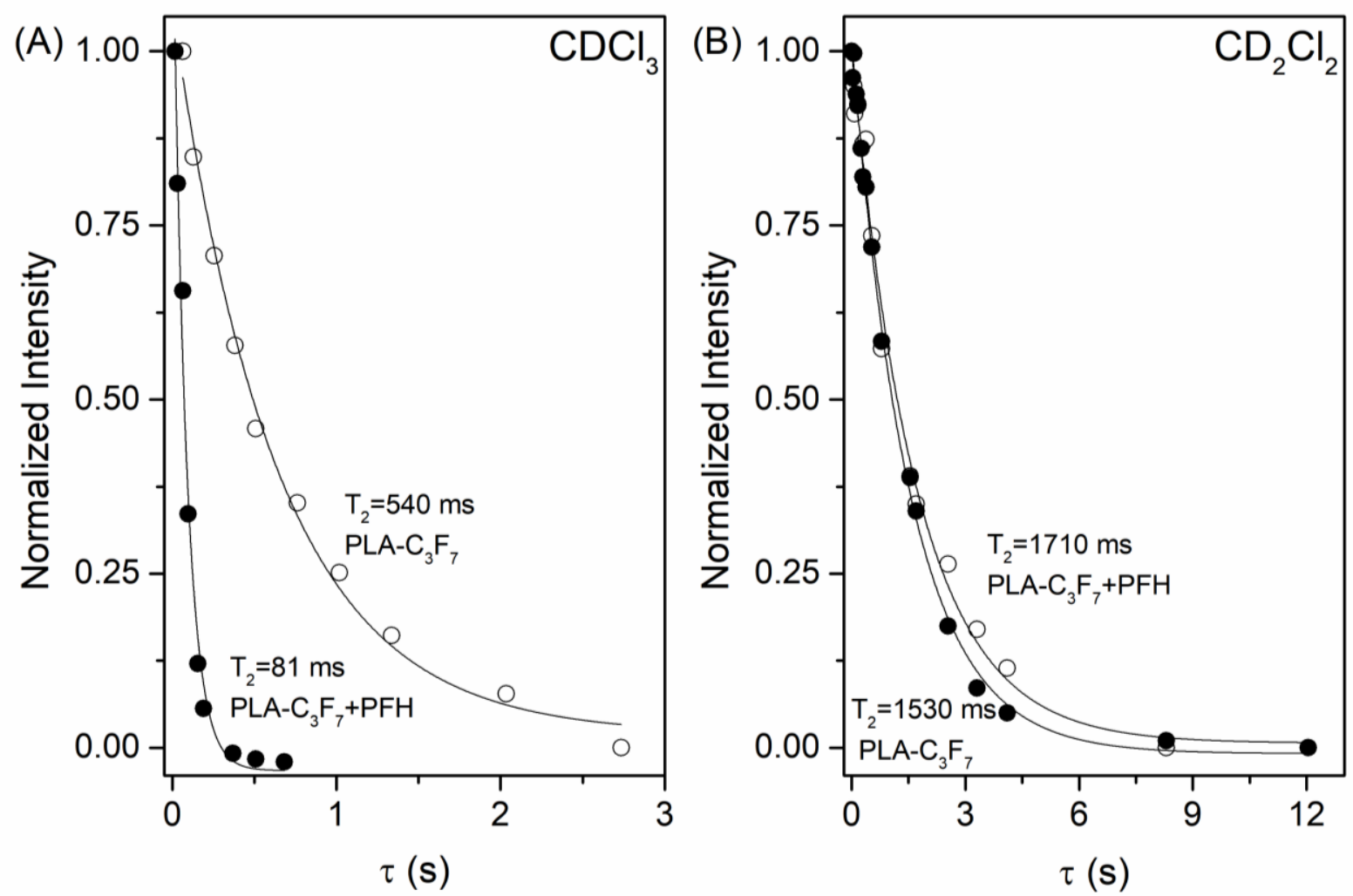

Figure 2. $T_{2}$ decay profiles for the $C_{3}$ resonance of $P L A-C_{3} F_{7}$ in $C C D C l_{3}(A)$ and $C_{2} C_{2}(B)$ without (open circles) and with perfluorohexane (dark circles).

According to those results, the introduction of PFH was able to reduce the local endfluorinated group mobility of $\mathrm{PLA}-\mathrm{C}_{3} \mathrm{~F}_{7}$ in $\mathrm{CDCl}_{3}$. As $\mathrm{PFH}$ is well dissolved in chloroform, its contact with the fluorinated units may lead to the formation of fluorophilic domains, a process that might also depends on the length of the fluorinated group. This scenario, however,

274 illustrates the system's behavior only in stable organic solutions; during the solventevaporation process in which MCs are formulated, transitory and thermodynamically unstable interfaces are created. Therefore, the ability of each fluorinated derivative to better stabilize and retain PFH as a liquid core was further studied in MCs formulations.

\subsection{Solvent Influence on MC formulation}

279 The impact of the fluorinated end-groups on the final morphology of microcapsules was then studied for all synthesized polymers. All microcapsules were initially formulated with fixed amounts of polymer $(50 \mathrm{mg})$ that were dissolved either in chloroform or dichloromethane and 
subsequently submitted to the same solvent-evaporation process. The encapsulation efficiency (EE) of PFH was quantified in freeze-dried samples by ${ }^{19} \mathrm{~F}-\mathrm{NMR}$ and the size of all MCs was measured by confocal microscopy as listed in Table 3.

Table 3. Encapsulation efficiency and size of microcapsules formulated with $50 \mathrm{mg}$ of polymer prepared in chloroform and dichloromethane.

\begin{tabular}{|c|c|c|c|c|}
\hline \multirow[t]{2}{*}{ Sample } & \multicolumn{2}{|c|}{ Chloroform } & \multicolumn{2}{|c|}{ Dichloromethane } \\
\hline & Size $(\mu \mathrm{m})^{*}$ & PFH EE (\%) & Size $(\mu \mathrm{m})^{*}$ & PFH EE (\%) \\
\hline $\mathrm{PLA}-\mathrm{C}_{6} \mathrm{H}_{13}$ & $4.2 \pm 1.0$ & $5.5 \pm 0.2$ & $4.8 \pm 0.8$ & $12.3 \pm 0.2$ \\
\hline $\mathrm{PLA}-\mathrm{C}_{3} \mathrm{~F}_{7}$ & $4.4 \pm 0.6$ & $10.1 \pm 0.2$ & $4.7 \pm 0.8$ & $9.1 \pm 0.1$ \\
\hline $\mathrm{PLA}-\mathrm{C}_{6} \mathrm{~F}_{13}$ & $4.8 \pm 1.0$ & $12.7 \pm 0.2$ & $4.6 \pm 1.0$ & $13.1 \pm 1.3$ \\
\hline PLA- ${ }_{8} \mathrm{~F}_{17}$ & $4.6 \pm 0.8$ & $10.3 \pm 0.5$ & $4.9 \pm 1.2$ & $11.1 \pm 0.2$ \\
\hline PLA- $C_{11} F_{23}$ & $5.2 \pm 1.4$ & $11.1 \pm 1.4$ & $4.8 \pm 0.9$ & $7.1 \pm 0.1$ \\
\hline PLA- ${ }_{13} F_{27}$ & $5.2 \pm 1.0$ & $11.4 \pm 1.5$ & $5.3 \pm 0.6$ & $10.0 \pm 0.7$ \\
\hline
\end{tabular}

*All measurements correspond to observation and analysis of at least 100 microcapsules per each group.

As determined by ${ }^{19} \mathrm{~F}$ NMR, the non-fluorinated polymer, PLA- $\mathrm{C}_{6} \mathrm{H}_{13}$, presented an encapsulation efficiency of $5.5 \pm 0.1 \%$ when prepared in $\mathrm{CHCl}_{3}$. The use of fluorinated polymers led to a 2 -fold increase in PFH encapsulation efficiency, reaching $11 \pm 3.0 \%$ without any significant distinction as a function of the fluorinated end-group length (Table 3). The reduced end-group mobility of fluorinated polymers in $\mathrm{CDCl}_{3}$ containing $\mathrm{PFH}$ was translated into higher encapsulation efficiencies. Altogether, these results evidence the ability of fluorinated polymers to interact with the fluorocarbon phase and enhance its stabilization inside the organic phase, as previously reported for nanocapsules ${ }^{14}$. For microcapsules prepared in $\mathrm{CH}_{2} \mathrm{Cl}_{2}$, no trend was observed for the encapsulation efficiency, probably due the absence of specific interactions between PFH and the polymer (Table 2).

Nonetheless, PLA or PLGA polymers are able to encapsulate higher amounts of PFH into MCs $(\sim 40 \%)^{13}$, the discrepancy with our results may be related to the fast process of solvent 
evaporation employed here, whereas Mousnier et al. have evaporated the organic solvent slowly at ambient pressure ${ }^{13}$.

Although all samples were predominately smooth as shown by SEM in Figures $\mathbf{3}$ and 4 (bottom), a certain amount of rough shelled MCs were also observed in all images. According to Chung, et al., this morphological variation might be related to the fast evaporation process used, which promoted an uneven polymer concentration gradient towards the interface ${ }^{41}$. Also, a partial PFH vaporization during the solvent evaporation step (performed at $30^{\circ} \mathrm{C}$ ) may have caused a volumetric expansion of the MCs and, as the temperature dropped, a subsequent shrinkage altered the continuous spreading of the polymer at the interface as previously reported by Lebeveda et al. for PFH containing microspheres ${ }^{42}$.

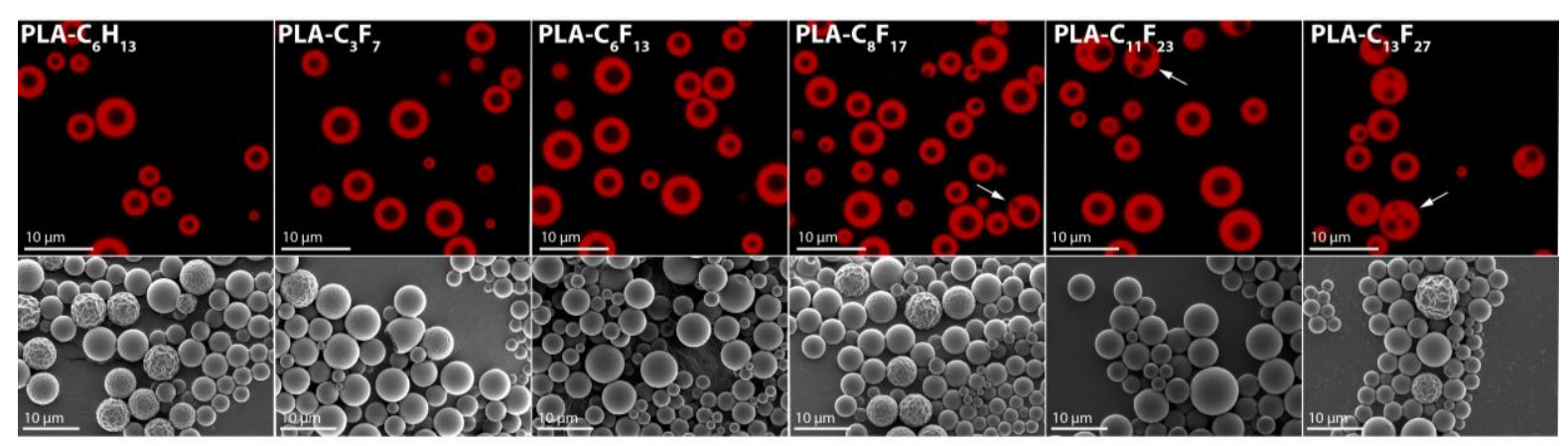

Figure 3. Confocal (top) and scanning electron microscopy (bottom) images of microcapsules produced in chloroform. Scale bar represents $10 \mu \mathrm{m}$.

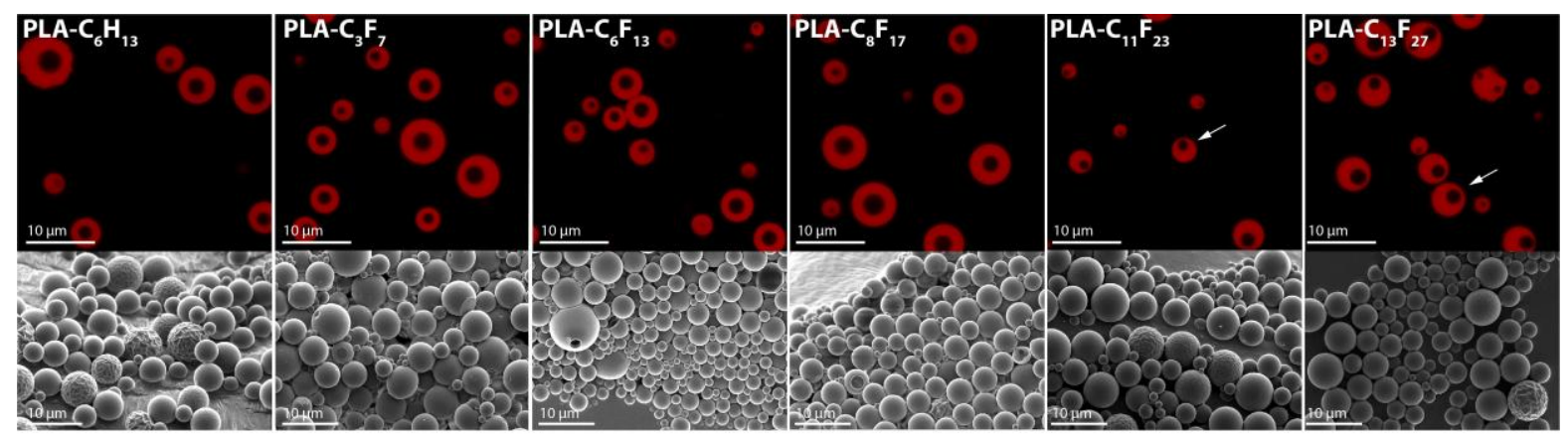

Figure 4. Confocal (top) and scanning electron microscopy (bottom) images of microcapsules produced in dichloromethane. Scale bar represents $10 \mu \mathrm{m}$. 
317 A clear and subtle distinction on MC morphology was observed according to the fluorinated 318 end-group length in both solvents. In all cases, PLA- $\mathrm{C}_{6} \mathrm{H}_{13}, P L A-\mathrm{C}_{3} \mathrm{~F}_{7}$ and $\mathrm{PLA}-\mathrm{C}_{6} \mathrm{~F}_{13}$ 319 exhibited core-shell morphologies comprising a well-centered PFH phase; however, as the 320 end-group length increased to $\mathrm{C}_{8} \mathrm{~F}_{17}, \mathrm{C}_{11} \mathrm{~F}_{23}$ and $\mathrm{C}_{13} \mathrm{~F}_{27}$ higher extents of randomly distributed 321 PFH cores were observed as displayed by the white arrows in Figures 3 and 4 (top). In $322 \mathrm{CH}_{2} \mathrm{Cl}_{2}, \mathrm{MCs}$ still possess a distinctive core shell structure but the inner $\mathrm{PFH}$ core is 323 displaced from the center of the MC. Such decentered morphology had already been 324 observed ${ }^{13}$. Formulation in $\mathrm{CHCl}_{3}$ leads to a mixture of structure with well centered $\mathrm{MC}$ and 325 with MC having multi-cores of PFH.

326 Regardless of the solvent employed, samples prepared with short fluorinated or non327 fluorinated end-groups, $\mathrm{PLA}-\mathrm{C}_{3} \mathrm{~F}_{7}$ and $\mathrm{PLA}-\mathrm{C}_{6} \mathrm{~F}_{13}$ or $\mathrm{PLA}-\mathrm{C}_{6} \mathrm{H}_{13}$, presented the formation of 328 core-shell capsules. Only MCs formulated with longer fluorinated groups, PLA- ${ }_{8} F_{17}$, PLA$329 \quad \mathrm{C}_{11} \mathrm{~F}_{23}$ and PLA- $\mathrm{C}_{13} \mathrm{~F}_{27}$, led to the appearance of different morphologies, either in chloroform 330 or dichloromethane, indicating that the shell precipitates prior to complete PFH nucleation at 331 the center of the organic droplet. Thus, the length of the fluorinated end-group played an 332 important role in the fluorocarbon nucleation process, suggesting that longer fluorous chains 333 were able to better interact and restrain the PFH diffusion as illustrated in Figure 5. 


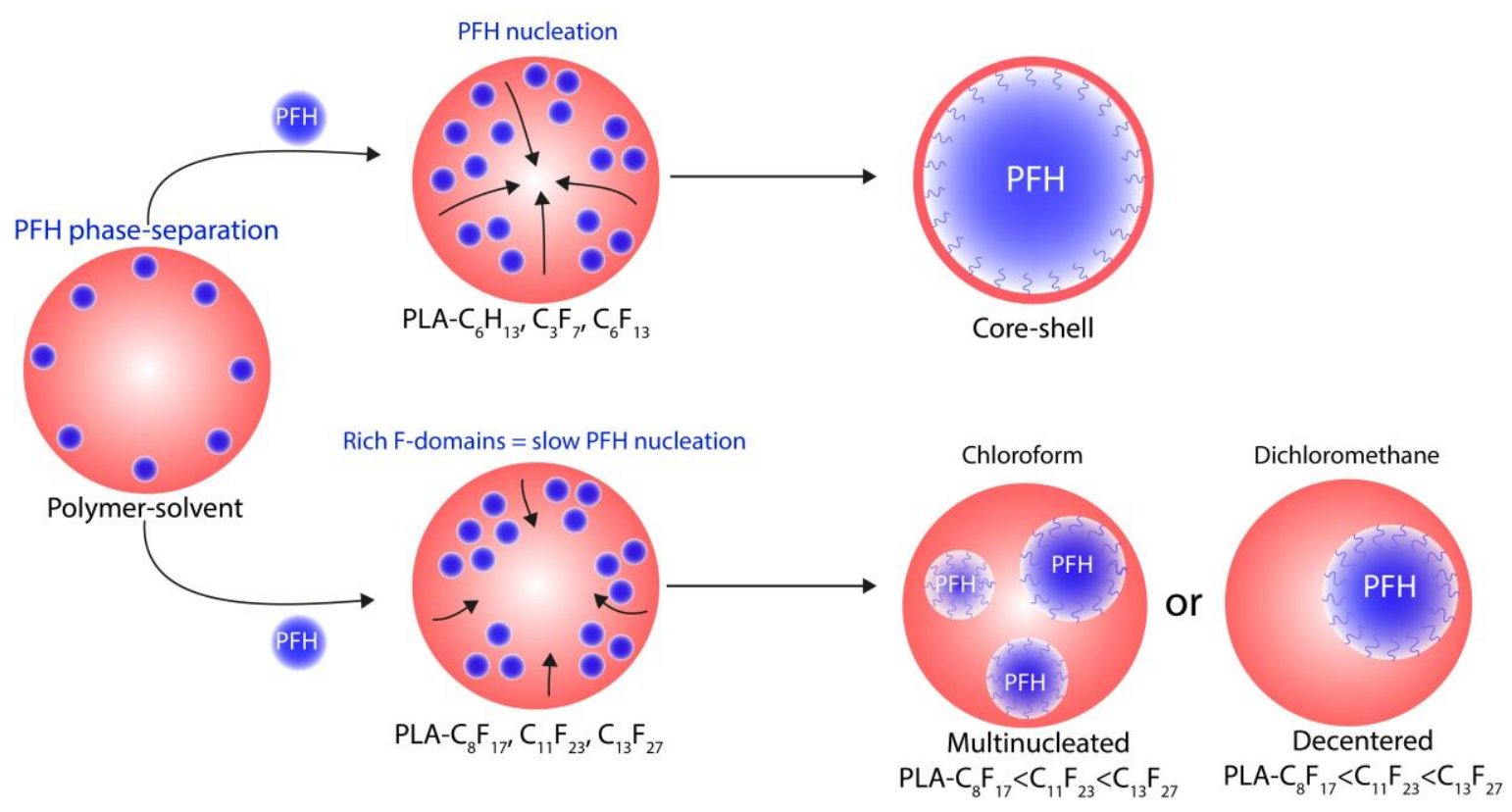

Figure 5. Schematic representation of the perfluorohexane phase-separation and nucleation process in the organic phase containing fluorinated polymers of distinct end-group lengths.

The different morphologies generated in each solvent are possibly related with the extent of fluorous interactions, PFH miscibility as well as solvent evaporation rate. In dichloromethane, the formation of decentered capsules for the longer F-units samples, such as PLA-C ${ }_{13} F_{27}$, probably reflected the reduced extent of interactions between the end-groups and $\mathrm{PFH}$. Nonetheless, such samples were still able to alter the nucleation pattern, inducing the PFH to accumulate towards the drop's periphery, also suggesting the fluorinated segregation effect. The obtained decentered morphologies are, however, favored by the solvent's lower boiling point $\left(39.6{ }^{\circ} \mathrm{C}\right.$ for $\mathrm{CH}_{2} \mathrm{Cl}_{2}$ vs. $61.2{ }^{\circ} \mathrm{C}$ for $\mathrm{CHCl}_{3}$ ) that accelerates the onset of polymer precipitation.

In chloroform, the shell of polymers with longer fluorinated groups precipitates before the complete fluorocarbon nucleation restraining PFH diffusion and causes multiple PFH cores 350 dispersed inside the rigid polymeric phase. As disclosed by $T_{2}$ results, the PFH is able to 351 interact more efficiently with the fluorinated end-groups in this solvent. Thus, such structure 
352 is probably attributable to formation of F-rich domains driven by the end-group polymer 353 arrangement to minimize contact with the surrounding polymer. This effect indicates that 354 longer fluorinated units interact more importantly with $\mathrm{PFH}$.

\subsection{Influence of polymer concentration on MC morphology}

To further evaluate the end-group chemistry and length influence on microcapsules structure, samples PLA- $\mathrm{C}_{6} \mathrm{H}_{13}, \mathrm{PLA}-\mathrm{C}_{3} \mathrm{~F}_{7}, \mathrm{PLA}-\mathrm{C}_{8} \mathrm{~F}_{17}$ and $\mathrm{PLA}-\mathrm{C}_{13} \mathrm{~F}_{27}$ were prepared only in chloroform using different polymer masses $(12.5,25,50$ and $100 \mathrm{mg})$ and constant PFH volume of 30 $\mu \mathrm{L}$.

Samples prepared with $12.5 \mathrm{mg}$ presented core-shell structures with thin and smooth polymer layers that were predominant for all polymers, independently of end-group chemistry or length as shown in Figure 6. The increase of polymer mass to $25 \mathrm{mg}$ altered only the morphology of MCs having the longest fluorinated group: PLA- $\mathrm{C}_{13} \mathrm{~F}_{27}$ by formation of multinucleated capsules $(42 \pm 10 \%)$ as displayed by the white arrow in Figure 6 . The percentage of multiple PFH cores for PLA- $\mathrm{C}_{13} \mathrm{~F}_{27}$ became more obvious for 50 and $100 \mathrm{mg}$, in which the total amount of multinucleated MCs increased from $60 \pm 5 \%$ to $91 \pm 3 \%$, respectively. The same effect but at a lower extent was observed for PLA- $\mathrm{C}_{8} \mathrm{~F}_{17}$, as thinshelled MCs are observed in the formulations containing $25 \mathrm{mg}$ and multinucleated morphologies increased from $10 \pm 2 \%$ to $56 \pm 7 \%$ for 50 and $100 \mathrm{mg}$, respectively. A similar behavior was observed for $\mathrm{MC}$ formulated with the polymer containing the shortest fluorine end-group, PLA- $\mathrm{C}_{3} \mathrm{~F}_{7}$, as core-shell structures predominated until a polymer mass of $100 \mathrm{mg}$, in which a total of $45 \pm 5 \%$ of multinucleated MC were found. In contrast, MC formulated with the non-fluorinated sample, $\mathrm{PLA}-\mathrm{C}_{6} \mathrm{H}_{13}$, exhibited core-shell morphologies for all of the tested polymer masses. 


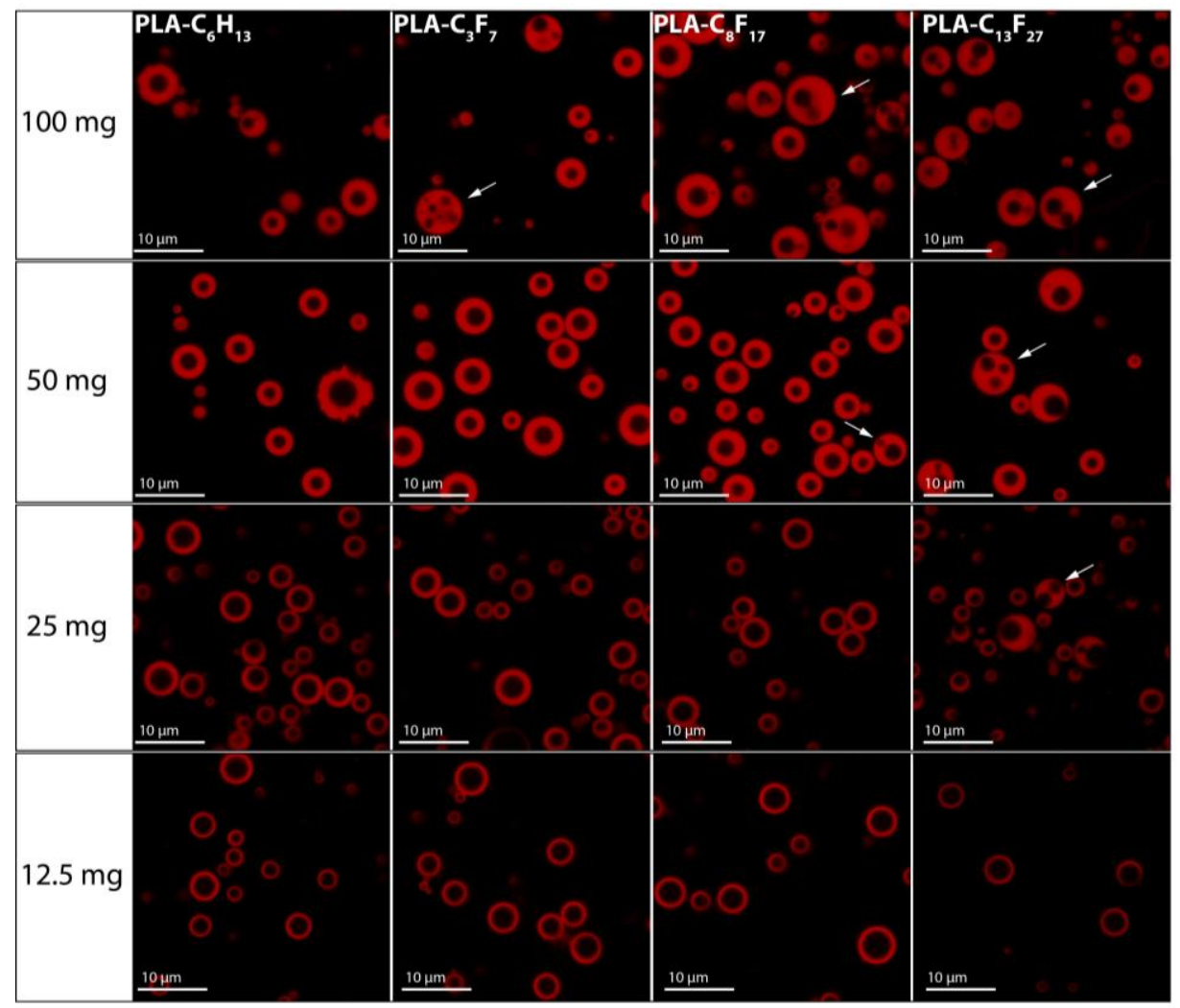

376 Figure 6. Confocal microscopy images of microcapsules formulated in chloroform with non-

377 fluorinated $\left(\mathrm{PLA}-\mathrm{C}_{6} \mathrm{H}_{13}\right)$ and fluorinated $\left(\mathrm{PLA}-\mathrm{C}_{3} \mathrm{~F}_{7}, \mathrm{PLA}-\mathrm{C}_{8} \mathrm{~F}_{17}\right.$ and $\left.\mathrm{PLA}-\mathrm{C}_{13} \mathrm{~F}_{27}\right)$ polymers with 378 varied polymer masses: $100,50,25$ and $12.5 \mathrm{mg}$. Scale bar of $10 \mu \mathrm{m}$.

379 Despite heterogeneity of morphology within the same sample, a clear effect of the polymer end-group chemistry and fluorinated length was evidenced in the capsule's morphology.

381 Compared to PLA-C ${ }_{6} \mathrm{H}_{13}$, polymers containing F-groups generated MCs with decentered 382 and/or multiple PFH cores. At high fluorinated polymer mass, the dominant morphology 383 whatever the fluorinated length block consists in multinucleated capsules. This increase in 384 polymer mass favored the formation of richer fluorophilic domains - in the order of $385 \quad \mathrm{C}_{3} \mathrm{~F}_{7}<\mathrm{C}_{8} \mathrm{~F}_{17}<\mathrm{C}_{13} \mathrm{~F}_{27}$ - that altered the polymeric phase dynamics, reducing the migration of 386 PFH to the center of the organic drop.

\section{Conclusion}

We have successfully synthesized and characterized poly(lactide) end-group fluorinated polymers for improved fluorous interaction with $\mathrm{PFH}$. The presence of fluorinated end-groups 
411 Number-average molar masses $(\mathrm{Mn})$ obtained by SEC/1H-NMR, dispersity and glass-

412 transition temperature $(\mathrm{Tg})$ of all polymers.

provided more favorable interfaces with perfluorohexane in organic solution of chloroform with fluorinated end-group length dependency, as revealed by spin-spin relaxation measurements. The formation of fluorophilic environment is reflected with improved perfluorohexane encapsulation efficiencies into microcapsules and by modifying the final morphology, particularly in the case of longer fluorinated end-groups and important polymer masses.

\section{Acknowledgements}

This work has been supported by the Région lle-de-France in the framework of DIM Nano-K and the French National Research Agency (ANR) under grant ANR-10-NANO-06 as part of the "Investissements d'Avenir" program. Institut Galien Paris-Sud is a member of the Laboratory of Excellence LERMIT supported by a grant from ANR (ANR-10-LABX-33). We are also thankful to Conselho Nacional de Desenvolvimento Científico e Tecnológico (CNPq) for the financial support, to Valerie Nicolas from MIPSIT for helping with confocal experiments, to Prof. Jaísa Soares as well as Prof. Jens Dittmer for their help with NMR relaxation experiments and to Carine Van-Heijenoort, Christina Sizun and Marc-André Delsuc for fruitful discussions.

\section{Supporting Information.}

${ }^{1} \mathrm{H}$ and ${ }^{19} \mathrm{~F}-\mathrm{NMR}$ spectra of all synthesized polymers in $\mathrm{CDCl} 3$.

SEC chromatogram of all polymers in chloroform at $30^{\circ} \mathrm{C}$. 
413 Spin-lattice relaxation (T1) values of correspondent ${ }^{19} \mathrm{~F}$ resonances for samples dissolved in $414 \mathrm{CDCl} 3$ and $\mathrm{CD} 2 \mathrm{Cl} 2$ with and without perfluorohexane.

\section{References}

417 (1) Krafft, M. P.; Riess, J. G. Perfluorocarbons: Life Sciences and Biomedical Uses Dedicated to the Memory of Professor Guy Ourisson, a True RENAISSANCE Man. J. Polym. Sci. Part a-Polymer Chem. 2007, 45 (7), 1185-1198. https://doi.org/10.1002/pola.21937.

(2) Krafft, M. P.; Riess, J. G. Chemistry, Physical Chemistry, and Uses of Molecular

(3) Shaffer, T. H.; Foust, R.; Wolfson, M. R.; Miller, T. F. Analysis of Perfluorochemical

(4) Cosco, D.; Fattal, E.; Fresta, M.; Tsapis, N. Perfluorocarbon-Loaded Micro and Nanosystems for Medical Imaging: A State of the Art. J. Fluor. Chem. 2015, 171. https://doi.org/10.1016/j.jluchem.2014.10.013.

(5) Pisani, E.; Tsapis, N.; Galaz, B.; Santin, M.; Berti, R.; Taulier, N.; Kurtisovski, E.; Lucidarme, O.; Ourevitch, M.; Doan, B. T.; et al. Perfluorooctyl Bromide Polymeric Capsules as Dual Contrast Agents for Ultrasonography and Magnetic Resonance Imaging. Adv. Funct. Mater. 2008, 18 (19). https://doi.org/10.1002/adfm.200800454.

(6) Jafari, S.; Diou, O.; Mamou, J.; Renault, G.; Fattal, E.; Tsapis, N.; Bridal Lori, S. HighFrequency (20 to $40 \mathrm{MHz}$ ) Acoustic Response of Liquid-Filled Nanocapsules. IEEE Trans. Ultrason. Ferroelectr. Freq. Control 2014, 61 (1). https://doi.org/10.1109/TUFFC.2014.6689771. 
(7) Diou, O.; Tsapis, N.; Giraudeau, C.; Valette, J.; Gueutin, C.; Bourasset, F.; Zanna, S.; Vauthier, C.; Fattal, E. Long-Circulating Perfluorooctyl Bromide Nanocapsules for Tumor Imaging by (FMRI)-F-19. Biomaterials 2012, 33 (22), 5593-5602. https://doi.org/10.1016/j.biomaterials.2012.04.037.

(8) Boissenot, T.; Fattal, E.; Bordat, A.; Houvenagel, S.; Valette, J.; Chacun, H.; Gueutin, C.; Tsapis, N. Paclitaxel-Loaded PEGylated Nanocapsules of Perfluorooctyl Bromide as Theranostic Agents. Eur. J. Pharm. Biopharm. 2016, 108, 136-144. https://doi.org/10.1016/j.ejpb.2016.08.017.

(9) Boissenot, T.; Bordat, A.; Larrat, B.; Varna, M.; Chacun, H.; Paci, A.; Poinsignon, V.; Fattal, E.; Tsapis, N. Ultrasound-Induced Mild Hyperthermia Improves the Anticancer Efficacy of Both Taxol® and Paclitaxel-Loaded Nanocapsules. J. Control. Release 2017, 264. https://doi.org/10.1016/j.jconrel.2017.08.041.

(10) Singh, R.; Husseini, G. A.; Pitt, W. G. Phase Transitions of Nanoemulsions Using Ultrasound: Experimental Observations. Ultrason. Sonochem. 2012, 19 (5), 11201125. https://doi.org/10.1016/J.ULTSONCH.2012.02.005.

(11) Li, H.; Wang, J.; Wang, P.; Zheng, J.; Song, F.; Yin, T.; Zhou, G.; Zheng, R.; Zhang, C. Phase-Transition Contrast Nanocapsules Triggered by Low-Intensity Ultrasound. Chem. Commun. 2014, 50 (96), 15163-15166. https://doi.org/10.1039/C4CC04641B.

(12) You, Y.; Wang, Z.; Ran, H.; Zheng, Y.; Wang, D.; Xu, J.; Wang, Z.; Chen, Y.; Li, P. Nanoparticle-Enhanced Synergistic HIFU Ablation and Transarterial Chemoembolization for Efficient Cancer Therapy. Nanoscale 2016, 8 (7), 4324-4339. https://doi.org/10.1039/C5NR08292G.

(13) Mousnier, L.; Huang, N.; Morvan, E.; Fattal, E.; Tsapis, N. Influence of Polymer EndChemistry on the Morphology of Perfluorohexane Polymeric Microcapsules Intended as Ultrasound Contrast Agents. Int. J. Pharm. 2014, 471 (1-2). https://doi.org/10.1016/j.jpharm.2014.05.012.

(14) Picheth, G.; Houvenagel, S.; Dejean, C.; Couture, O.; Alves de Freitas, R.; Moine, L.; Tsapis, N. Echogenicity Enhancement by End-Fluorinated Polylactide 
Perfluorohexane Nanocapsules: Towards Ultrasound-Activable Nanosystems. Acta

Biomater. 2017, 64. https://doi.org/10.1016/j.actbio.2017.10.002.

(15) Astafyeva, K.; Somaglino, L.; Desgranges, S.; Berti, R.; Patinote, C.; Langevin, D.; Lazeyras, F.; Salomir, R.; Polidori, A.; Contino-Pépin, C.; et al. Perfluorocarbon Nanodroplets Stabilized by Fluorinated Surfactants: Characterization and Potentiality as Theranostic Agents. J. Mater. Chem. B 2015, 3 (14), 2892-2907. https://doi.org/10.1039/C4TB01578A.

(16) Fernandes, D. A.; Fernandes, D. D.; Li, Y.; Wang, Y.; Zhang, Z.; Rousseau, D.; Gradinaru, C. C.; Kolios, M. C. Synthesis of Stable Multifunctional Perfluorocarbon Nanoemulsions for Cancer Therapy and Imaging. Langmuir 2016, 32 (42), 1087010880. https://doi.org/10.1021/acs.langmuir.6b01867.

(17) Oda, Y.; Suzuki, R.; Mori, T.; Takahashi, H.; Natsugari, H.; Omata, D.; Unga, J.; Uruga, H.; Sugii, M.; Kawakami, S.; et al. Development of Fluorous Lipid-Based Nanobubbles for Efficiently Containing Perfluoropropane. Int. J. Pharm. 2015, 487 (12), 64-71. https://doi.org/10.1016/J.IJPHARM.2015.03.073.

(18) Koda, Y.; Terashima, T.; Sawamoto, M. Fluorinated Microgel Star Polymers as Fluorous Nanocapsules for the Encapsulation and Release of Perfluorinated Compounds. Polym. Chem. 2015, 6 (31), 5663-5674. https://doi.org/10.1039/c5py00113g.

(19) Houvenagel, S.; Picheth, G.; Dejean, C.; Brulet, A.; Chenneviere, A.; Couture, O.; Huang, N.; Moine, L.; Tsapis, N. End-Chain Fluorination of Polyesters Favors Perfluorooctyl Bromide Encapsulation into Echogenic PEGylated Nanocapsules. Polym. Chem. 2017, 8 (16), 2559-2570. https://doi.org/10.1039/C7PY00400A.

(20) Houvenagel, S.; Moine, L.; Picheth, G.; Dejean, C.; Brûlet, A.; Chennevière, A.; Faugeras, V.; Huang, N.; Couture, O.; Tsapis, N. Comb-Like Fluorophilic-LipophilicHydrophilic Polymers for Nanocapsules as Ultrasound Contrast Agents.

Biomacromolecules 2018, 19 (8), 3244-3256.

https://doi.org/10.1021/acs.biomac.8b00506. 
(21) Kaberov, L. I.; Verbraeken, B.; Hruby, M.; Riabtseva, A.; Kovacik, L.; Kereïche, S.; Brus, J.; Stepanek, P.; Hoogenboom, R.; Filippov, S. K. Novel Triphilic Block Copolymers Based on Poly(2-Methyl-2-Oxazoline)- Block -poly(2-Octyl-2-Oxazoline) with Different Terminal Perfluoroalkyl Fragments: Synthesis and Self-Assembly Behaviour. Eur. Polym. J. 2017, 88, 645-655. https://doi.org/10.1016/j.eurpolymj.2016.10.016.

(22) Kaberov, L. I.; Verbraeken, B.; Riabtseva, A.; Brus, J.; Talmon, Y.; Stepanek, P.; Hoogenboom, R.; Filippov, S. K. Fluorinated 2-Alkyl-2-Oxazolines of High Reactivity: Spacer-Length-Induced Acceleration for Cationic Ring-Opening Polymerization As a Basis for Triphilic Block Copolymer Synthesis. ACS Macro Lett. 2018, 7(1), 7-10. https://doi.org/10.1021/acsmacrolett.7b00954.

(23) Riabtseva, A.; Kaberov, L. I.; Noirez, L.; Ryukhtin, V.; Nardin, C.; Verbraeken, B.; Hoogenboom, R.; Stepanek, P.; Filippov, S. K. Structural Characterization of Nanoparticles Formed by Fluorinated Poly(2-Oxazoline)-Based Polyphiles. Eur. Polym. J. 2018, 99, 518-527. https://doi.org/10.1016/J.EURPOLYMJ.2018.01.007.

(24) Kaberov, L. I.; Verbraeken, B.; Riabtseva, A.; Brus, J.; Radulescu, A.; Talmon, Y.; Stepanek, P.; Hoogenboom, R.; Filippov, S. K. Fluorophilic-Lipophilic-Hydrophilic Poly(2-Oxazoline) Block Copolymers as MRI Contrast Agents: From Synthesis to SelfAssembly. Macromolecules 2018, 51 (15), 6047-6056. https://doi.org/10.1021/acs.macromol.8b00957.

(25) Horváth, I. T. Fluorous Biphase Chemistry. Acc. Chem. Res. 1998, 31 (10), 641-650. https://doi.org/10.1021/ar970342i.

(26) Koda, Y.; Terashima, T.; Sawamoto, M.; Maynard, H. D. Amphiphilic/Fluorous Random Copolymers as a New Class of Non-Cytotoxic Polymeric Materials for Protein Conjugation. Polym. Chem. 2015, 6, 240-247. https://doi.org/10.1039/C4PY01346H.

(27) Singh, A.; Naskar, A. K.; Haynes, D.; Drews, M. J.; Smith, D. W. Synthesis, Characterization and Surface Properties of Poly(Lactic Acid)-Perfluoropolyether Block Copolymers. Polym. Int. 2011, 60 (3), 507-516. https://doi.org/10.1002/pi.2982. 
(28) Giuntoli, G.; Rosi, L.; Frediani, M.; Sacchi, B.; Frediani, P. Fluoro-Functionalized PLA Polymers as Potential Water-Repellent Coating Materials for Protection of Stone. J. Appl. Polym. Sci. 2012, 125 (4), 3125-3133. https://doi.org/10.1002/app.36469.

(29) Diou, O.; Fattal, E.; Delplace, V.; Mackiewicz, N.; Nicolas, J.; Mériaux, S.; Valette, J.; Robic, C.; Tsapis, N. RGD Decoration of PEGylated Polyester Nanocapsules of Perfluorooctyl Bromide for Tumor Imaging: Influence of Pre or Post-Functionalization on Capsule Morphology. Eur. J. Pharm. Biopharm. 2014, 87 (1), 170-177. https://doi.org/10.1016/j.ejpb.2013.12.003.

(30) Aguilar, J. A.; Nilsson, M.; Bodenhausen, G.; Morris, G. A. Spin Echo NMR Spectra without J Modulation. Chem. Commun. 2012, 48 (6), 811-813. https://doi.org/10.1039/C1CC16699A.

(31) Henderson, T. J. Quantitative NMR Spectroscopy Using Coaxial Inserts Containing a Reference Standard: Purity Determinations for Military Nerve Agents. Anal. Chem. 2002, 74 (1), 191-198. https://doi.org/10.1021/ac010809+.

(32) Böhmer, M. R.; Schroeders, R.; Steenbakkers, J. A. M.; de Winter, S. H. P. M.; Duineveld, P. A.; Lub, J.; Nijssen, W. P. M.; Pikkemaat, J. A.; Stapert, H. R. Preparation of Monodisperse Polymer Particles and Capsules by Ink-Jet Printing. Colloids Surfaces A Physicochem. Eng. Asp. 2006, 289 (1-3), 96-104. https://doi.org/10.1016/J.COLSURFA.2006.04.011.

(33) Agrawal, A.; Saran, A. D.; Rath, S. S.; Khanna, A. Constrained Nonlinear Optimization for Solubility Parameters of Poly(Lactic Acid) and Poly(Glycolic Acid) - Validation and Comparison. Polymer (Guildf). 2004, 45 (25), 8603-8612. https://doi.org/10.1016/j.polymer.2004.10.022.

(34) Foster, T.; Dorfman, K. D.; Ted Davis, H. Giant Biocompatible and Biodegradable PEG-PMCL Vesicles and Microcapsules by Solvent Evaporation from Double Emulsion Droplets. J. Colloid Interface Sci. 2010, 351 (1), 140-150. https://doi.org/10.1016/J.JCIS.2010.05.020.

(35) Berger, R.; Resnati, G.; Metrangolo, P.; Weber, E.; Hulliger, J. Organic Fluorine 
Compounds: A Great Opportunity for Enhanced Materials Properties. Chem. Soc. Rev. 2011, 40 (7), 3496. https://doi.org/10.1039/c0cs00221f.

(36) Ojogun, V.; Knutson, B. L.; Vyas, S.; Lehmler, H.-J. Fluorophilicity of Alkyl and Polyfluoroalkyl Nicotinic Acid Ester Prodrugs. J. Fluor. Chem. 2010, 131 (7), 784-790. https://doi.org/10.1016/J.JFLUCHEM.2010.04.001.

(37) Shen, J.; Piunova, V. A.; Nutt, S.; Hogen-Esch, T. E. Blends of Polystyrene and Poly(n-Butyl Methacrylate) Mediated by Perfluorocarbon End Groups. Polymer (Guildf). 2013, 54 (21), 5790-5800. https://doi.org/10.1016/J.POLYMER.2013.08.059.

(38) Marchione, A. A.; Buck, R. C. Complete Multinuclear Magnetic Resonance Characterization of a Set of Polyfluorinated Acids and Alcohols. Magn. Reson. Chem. 2009, 47 (2), 194-198. https://doi.org/10.1002/mrc.2376.

(39) Twum, E. B.; Gao, C.; Li, X.; McCord, E. F.; Fox, P. A.; Lyons, D. F.; Rinaldi, P. L. Characterization of the Chain-Ends and Branching Structures in Polyvinylidene Fluoride with Multidimensional NMR. Macromolecules 2012, 45 (13), 5501-5512. https://doi.org/10.1021/ma300835s.

(40) Kadayakkara, D. K.; Damodaran, K.; Hitchens, T. K.; Bulte, J. W. M.; Ahrens, E. T. 19F Spin-lattice Relaxation of Perfluoropolyethers: Dependence on Temperature and Magnetic Field Strength (7.0-14.1 T). J. Magn. Reson. 2014, 242, 18-22. https://doi.org/10.1016/J.JMR.2014.01.014.

(41) Chung, T.-W.; Huang, Y.-Y.; Liu, Y.-Z. Effects of the Rate of Solvent Evaporation on the Characteristics of Drug Loaded PLLA and PDLLA Microspheres. Int. J. Pharm. 2001, 212 (2), 161-169. https://doi.org/10.1016/S0378-5173(00)00574-3.

(42) Lebedeva, N. V.; Sanders, S. N.; Ina, M.; Zhushma, A. P.; Olson, S. D.; Rubinstein, M.; Sheiko, S. S. Multicore Expandable Microbubbles: Controlling Density and Expansion Temperature. Polymer (Guildf). 2016, 90, 45-52. https://doi.org/10.1016/J.POLYMER.2016.02.050. 